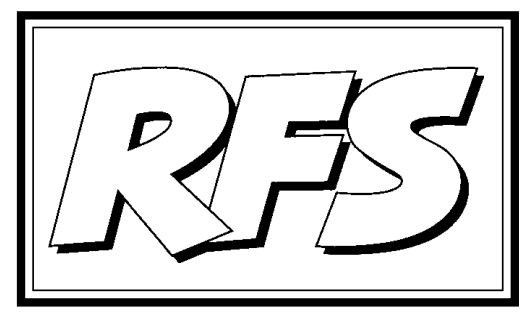

Revista de Fomento Social, 57 (2002), 711-724

\title{
¿Qué esperanzas para Brasil?
}

\section{Bernard LESTIENNE}

Seis meses antes de los resultados de las elecciones del 27 de octubre de 2002, nadie hubiera apostado por la victoria de Luiz Inácio Lula da Silva, "Lula". Satisfecho de lo que había hecho durante sus dos mandatos (19951998 y 1999-2002), el presidente Fernando Henrique Cardoso (FHC) había declarado públicamente que transmitiría la banda presidencial al candidato de su partido, el PSDB ${ }^{2}$. ¿Acaso no habían dicho los brasileños por tres veces no al sindicalista del metal de São Paulo, candidato del Partido de los trabajadores (PT)? la 'derecha' estaba segura de sí misma.

$Y$, sin embargo, Lula fue elegido por una gran mayoría $(61,4 \%$ contra $38,6 \%)$. Durante to da la campaña, con gran carisma, encarnó al mismo tiempo la moderación y el cambio, la confianza y la esperanza. Lula, el radical de las

1 Jesuita. CIAS (Centro de Investigación y Acción Social de la Compañía de Jesús en Brasil); IBRADES (Instituto Brasileño de Desarrollo Económico y Social encargado al CIAS por la Conferencia Episcopal Brasileña). Traducción del original francés a cargo de la redacción de la Revista; texto castellano revisado por el autor.

2 PSDB $=$ Partido Social Demócrata Brasileño 
campañas anteriores, se había transformado en "Lula, paz y amor", como lo caracterizan los medios de comunicación. Su programa económico ortodoxo tranquilizó en partea los mercados. Tenía a su al rededor un excelente equipo unido de consejeros mediáticos, políticos y económicos. Lula había viajado mucho por to do el país y mantenía un contacto directo con el conjunto de la población. Expresaba las aspiraciones y los valores del Brasil profundo, que pocos, de hecho, conocen tan bien como él. Esta vez, muchos superaron sus prejuicios frente a un hombre que consideraban demasiado parecido a ellos para poder gobernar el país.

Pero la imagen moderada no hubiera bastado para asegurar la victoria. ¿Cómo explicar que un obrero, mecánico, que perdió tres veces las elecciones, haya sido elegido para gobernar ese inmenso país que es Brasil, una de las diez mayores economías mundiales, uno de los países más desiguales del planeta, entonces hundido en plena crisis económica? La victoria de Lula es la expresión de una profunda insatisfacción del conjunto de la población, de la pequeña burguesía, de la clase media, y de los sectores pobres y marginados. Es el rechazo del modelo de desarrollo neoliberal implantado a marchas forzadas durante los años de FHC. La pobreza no disminuyó y las desigualdades aumentaron. FHC no cumplió sus promesas de luchar contra ambas. Muchos tienen la sensación de que los profundos cambios económicos beneficiaron ante todo a los ricos.

\section{Los años de FHC}

Sin duda, ha habido algunos avances. En el terreno político, progresa la implantación de los partidos en el ámbito nacional y éstos se refuerzan en perjuicio de los 'caciques' locales. Los cambios de partido a lo largo de la legislatura, en función de los intereses individuales, son menos numerosos. A pesar del control de los medios de comunicación por las 'élites' dirigentes, la libertad de expresión de la oposición y de los movimientos sociales y populares fue más respetada. La lucha contra la corrupción, todavía muy extendida, se reforzó.

El plan Real ${ }^{3}$ rompió la tendencia inflacionista. La estabilidad financiera, mantenida a un coste social muy elevado, estimuló las inversiones extranje-

3 El real (plural: reais) es la nueva moneda creada en julio de 1994, por FHC, siendo ministro de finanzas. Entonces valía 1,15 dólares. Hoy un dólar vale de media 3,5 reais. 
ras y aumentó el poder adquisitivo de ciertos sectores de la población.

Algunos indicadores sociales mejoraron, a pesar de que los progresos son todavía demasiado restringidos con relación a las necesidades de la población y a las potencialidades del país. En el terreno de la educación, se incrementó el acceso a la escuela primaria y el analfabetismo retrocede, pero la calidad de la enseñanza deja mucho que desear, y las desigualdades de educación entre los más ricos y los pobres han aumentado. En el terreno de la sanidad, también ha habido algunos avances: descenso de la mortalidad infantil, campañas de vacunación, lucha preventiva contra el SIDA, pero la extrema escasez de recursos sacrifica la calidad de los cuidados médicos en los establecimientos públicos. La privatización de la sanidad se generaliza, reservada sin embargo a los más pudientes. Hubo algunas compensaciones sociales, pero ante todo para atenuar el aumento de la pobreza y de las desigualdades.

La política económica de los años de FHC fue la del "Consenso de Washington". Apertura de las fronteras, liberalización de los flujos financieros, del comercio de bienes y servicios, privatización de sectores clave de la economía, desregulación, competitividad, reducción del papel del Estado, etc.: las recetas neoliberales fueron aplicadas con verdadero celo. A los ojos del FMI, Brasil es uno de los mejores alumnos de la clase... La ley del mercado deviene el nuevo paradigma de organización social. Como en todas partes, esta lógica ha reforzado a los fuertes y ha debilitado a los débiles.

FHC ha optado por modernizar el país: había que internacionalizarlo, introducirlo, a cualquier precio, en el mercado mundial. Para lograr este objetivo, la prioridad principal, si no la única, fue la estabilidad financiera.

Brasil abrió sus fronteras. El mercado se inundó de productos extranjeros a los que la producción nacional, todavía poco competitiva, no podía presentar batalla. Las importaciones aumentaron sensiblemente, mientras que la política del 'real fuerte'4 bloqueaba las exportaciones. Desde 1995, la balanza comercial, tradicio nalmente positiva, pasó a ser negativa. El gobierno compensó la falta de recursos multiplicando los préstamos y las privatizaciones. Las principales empresas públicas (financieras, mineras, siderúrgicas, energéticas, de electricidad, de telecomunicaciones, de investigación, etc.) fueron vendidas a empresas extranjeras, a un ritmo acelerado y a

4 De agosto 1994 a enero 1999, una real valía 1,15 dólares, y el tipo de cambio fue mantenido al precio de un notable incremento de los préstamos en el mercado exterior. 
precios infravalorados. Pero los contratos de venta fueron débiles, y las inversiones subsiguientes no se produjeron. Así, por ejemplo, la producción de energía eléctrica resultó insuficiente en 2001; los cortes fueron severos.

Para atraer a los capitales extranjeros, el Banco Central fijó unos tipos de interés de los más elevados del mundo ${ }^{5}$. Los capitales se orientaron ante todo hacia la compra de empresas, luego, de una manera más especulativa, hacia la compra de bonos del tesoro (títulos públicos). La inversión extranjera no se orientó hacia la producción. La explosión de la burbuja especulativa y el enfriamiento de la economía mundial a finales del año 2000 disminuyeron la entrada de capitales extranjeros. Estos han disminuido un $50 \%$ para el conjunto de América Latina en 2002; en Brasil pasaron de 30 mil millones de dólares en 2000 a 16 mil millones en 2002; el déficit de la balanza de pagos aumentó otro tanto.

La política del 'real fuerte' ha costado cara al país. A pesar de las presiones especulativas, FHC quiso mantener, costase lo que costase, la paridad favorable del real con respecto al dólar para asegurar su reelección en 1998. Desde 1999, el real se devaluó un 40\%. Luego el Banco Central lo deja 'flotar'. Pero para entonces el déficit comercial y la deuda pública habían aumentado demasiado.

Tales opciones financieras pesaron mucho sobre la evolución económica del país. En enero de 1999 Brasil firmó un primer acuerdo con el FMI. Las exigencias de éste fueron semejantes a las de los ajustes estructurales en otros países: reducción del déficit fiscal, control reforzado de la inflación, aumento del beneficio primario, mantenimiento de tipos de interés elevados, etc. La desaceleración de la economía fue progresiva, acentuada por el contexto internacional. En cuatro años, Brasil ha firmado tres acuerdos, multiplicando los préstamos; pero la situación no ha mejorado. De hecho, demasiado volcado hacia el exterior, el país se hizo cada vez más dependiente del entorno mundial, y vulnerable a las fluctuaciones de los mercados financieros. Aumentaron las presiones sobre el real. El marasmo económico general de América Latina y la bancarrota de Argentina ralentizaron to davía más los intercambios. No se pudo conseguir el equilibrio fiscal y de la balanza de pagos sino a base de acelerar los préstamos. El aumento de la deuda redujo la confianza de los inversores. Y el círculo vicioso de la deuda se acentúa.

5 En noviembre de 2002, el tipo medio era del $22 \%$.

\section{RFS}


La explosión de la deuda pública sigue siendo la herencia más negativa del gobierno de FHC. A finales de noviembre de 2002 alcanzaba el $68 \%$ del PIB. En 1995, la deuda externa representaba el $27,9 \%$ del PIB, y el servicio de la misma (principal eintereses) representaba el $38,9 \%$ de las exportaciones; hoy en día representa el $44,2 \%$ del PIB y el servicio de la deuda el $92,7 \% \%$ de las exportaciones. En 8 años, la deuda externa prácticamente se ha duplicado, pasando de 120 a 235 mil millones de dólares; la deuda interna se ha multiplicado por 12, pasando de 70 mil millones a 860 mil millones de reais ( 0 sea, alrededor de 260 mil millones de dólares).

Pero, sobre todo, es la misma estructura dela deuda pública ${ }^{6}$ la que la hace peligrosa y aumenta la vulnerabilidad del país. Es volátil y oscila fácilmente. La mitad de la deuda pública está indexada con el dólar; poco más de un tercio depende de tipos de interés específicos ( ¡del 25\% desde octubre 2002!) y cerca del $40 \%$ de los préstamos lo son a menos de un año. Las oscilaciones del dólar con relación al real ( $+52,3 \%$ en 2002), y los tipos de interés muy elevados son las causas principales del encarecimiento o de la reducción de la deuda.

La prioridad de FHC fue la estabilidad financiera, con gran satisfacción de los acreedores. La política social fue, de hecho, sacrificada, tratada como marginal y anexa. Mientras que la producción industrial se ha ralentizado estos últimos años, los beneficios de los bancos y otros organismos financieros nunca fueron tan elevados. El aumento de la deuda y del desempleo (cfr. infra) ha acentuado las desigualdades, ya muy grandes, entre el $10 \%$ más rico y el $50 \%$ más pobre, entre las regiones de este país-continente, entre el campo y la ciudad, entre las periferias y los barrios residenciales.

Las medidas paliativas esconden mal la pobreza y la miseria. Según los dos principales institutos oficiales de estadística, en 2000, de los 172 millones de brasileños, 54 vivían bajo la línea de pobreza; de ellos, 15 vivían en la miseria. "Brasil no es un país pobre, sino un país donde hay muchos pobres", decía FHC en 1995 al asumir la presidencia, y prometía luchar contra la pobreza. De hecho, el número de pobres no ha disminuido, y nada serio se ha hecho para atajar las causas del mal.

Por el contrario, se ha asistido al desmantelamiento de una estructura intermedia de producción y a un aumento peligroso del desempleo. En la región industrial de São Paulo, que en parte refleja la situación del país, nunca

6 La deuda pública está compuesta de la parte pública de la deuda externa y de la deuda interna. 
el desempleo fuetan elevado, desde que se tienen cálculos ( 30 años). La parte del sector informal (en que los trabajadores no tienen ninguna protección legal ni seguridad presente ni futura) en el mercado de trabajo pasó en 8 años del $47,5 \%$ al $56 \%$. Los salarios de la función pública han estado bloqueados durante 8 años y su poder adquisitivo ha disminuido en torno a un $60 \%$. Hoy día el salario mínimo, que perciben alrededor del $30 \%$ de los asalariados, se acerca a los 65 dólares; apenas permite comprar la 'canasta básica', es decir, la alimentación y los productos básicos para 4 personas. Hay mucha desesperación y revuelta latentes entre los trabajadores y los pobres.

Paralelamenteal aumento del paro -y como consecuencia parcial de éstela violencia se intensifica. En particular, aumenta el exterminio de los jóvenes, víctimas de la policía o del enfrentamiento entre bandas de traficantes de droga. La calle es el recurso de aquellos cuyas familias se encuentran desestructuradas por la falta de condiciones mínimas para llevar una vida 'normal'. Los sucesivos planes de seguridad, a base de una represión más fuerte, no han resuelto nada, ya que ignoran las raíces del mal.

A finales de 2002, FHC transmite a Lula un país en pésima situación. Nunca, según ciertos analistas, un nuevo presidente ha heredado una situación tan frágil. Situación que se ha degradado sensiblemente en ese año 2002. Las cajas están vacías. La inflación amenaza de nuevo; ese año ha alcanzado el $25 \%$. El real ha perdido el $52,3 \%$ de su valor a lo largo del mismo año. La economía del país está en punto muerto, amenazada de 'estagflación' (inflación y recesión). Las inversiones se han paralizado y el mercado financiero internacional duda del próximo futuro del país. Los capitales (nacionales e internacionales) vuelan hacia otros lugares más seguros.

\section{La victoria de Lula}

En este contexto tan moroso se desarrolló la campaña electoral. Frente a las dificultades, en respuesta a la decepción o al desánimo de muchos, Lula ha transmitido esperanza. La clase media, víctima del desempleo, de una pérdida de poder adquisitivo y de un constante aumento de los impuestos, y el electorado popular, víctima de la pobreza y de la violencia, han perdido el miedo al cambio.

¡Extraña ascensión del pequeño vendedor de la calle desde el puerto de Santos hasta la suprema magistratura! Un recorrido inimaginable; jun cuento de hadas político! ¿Cómo ha podido este hombre superar los múltiples 
prejuicios contra sus modestos orígenes, movilizar a todo su país y hacerse elegir Presidente de la República? Su nacimiento, en 1945, en una pobre familia numerosa del Nordeste, parecía destinarle a la miseria. De pequeño, su madre lo lleva con toda la familia al puerto de Santos, cerca de São Paulo. $\checkmark a$ a la escuela, y para sostener a la familia, vende frutas y legumbres en las aceras y trabaja también como limpiabotas. Comienza a trabajar a los 12 años. A los 14, entra en una fábrica metalúrgica de la periferia de São Paulo. En el trabajo, pierde su dedo meñique izquierdo. Sigue un curso de mecánico tornero. Lula se casa a los 24 años y pierde a su mujer y a su hijo en el primer alumbramiento. Se vuelve a casar a los 29 años con Marisa, su actual esposa, viuda también.

A los 21 años comienza a frecuentar el sindicato. Pronto se revela como un líder nato. En 1975, en plena dictadura militar, en que la represión contra cualquier 'desorden' es violenta, Lula es elegido presidente del Sindicato de la metalurgia de Sãn Bernard o y Diadema ${ }^{7}$. Organiza un sindicalismo combativo y anima las primeras huelgas de 1978 y 1979. En 1980, los militares lo encarcelan durante un mes y rompen su mandato sindical.

En 1980, Lula es el actor principal de la fundación del partido de los trabajadores (PT), del que es elegido presidente. Y en 1983 participa en la fundación de la CUT (Central Única de Trabajadores) que agrupa a los sindicatos combativos. En 1982 es candidato al puesto de gobernador del estado de São Paulo y, aunque sin recursos y vilipendiado por los medios de comunicación, obtiene un número de votos importante. Es elegido diputado federal en 1986 y defenderá eficazmente los derechos de los trabajadores en la preparación de la Constitución de 1988. En 1989, 1994 y 1998, fue tres veces candidato a la presidencia de la República. Precisamente encuentra más prejuicios entre la gente sencilla. No se desanima. En 2002, Lula cambia sensiblemente su lenguaje y su presentación, y conquista la simpatía de una gran parte del electorado, en todos los medios sociales.

Lula es una figura carismática, un líder y negociador respetado tanto por sus partidarios como por sus adversarios ( inumerosos, por cierto!). Sigue cercano a la gente, habla su lenguaje, conoce su vida. Durante 20 años, construyó el PT viajando por todo el país, que conoce mejor que nadie. Ha

7 En la periferia de São Paulo, en las ciudades de Santo André, São Bernardo, São Caetano y Diadema, se sitúan entonces las principales fábricas metalúrgicas del país. Es allí donde se organizó poco a poco el sector más avanzado de la clase obrera de Brasil. 
sabido mantener la unidad del partido. Reúne a su alrededor hombres y corrientes diversas, del sindicalismo, de la política, de los movimientos sociales, toda la parte de la Iglesia de las comunidades eclesiales de base, intelectuales y trabajadores. Nunca fue contestado su liderato. Tranquilo y constante, inspira confianza. Hombrevaliente, de lucha, tenaz, perseverante, fiel; no sabe perder.

Su personalidad está marcada por su madre, una mujer pobre y valiente, a la que siempre profesó la mayor admiración, y por las pruebas de la vida: conocer el hambre, el trabajo duro desde la infancia, la fatiga del trabajo nocturno y la explotación obrera, las humillaciones ligadas a la pobreza, la pérdida de su mujer en un hospital público miserable, por carecer de recursos.

Ha sabido resistir al atractivo del poder, y sigue muy ligado a la gente sencilla, a los trabajadores. Hasta su elección a la Presidencia, ha seguido viviendo en São Bernardo, en las afueras de São Paulo. Le gusta el contacto directo. Su descanso: jestar con su familia y cocinar!

Lula no es un radical, pero está marcado por la indignación de los sufrimientos por los que pasó y muchos de sus conciudadanos deben todavía padecer. Su lenguaje puede ser a veces combativo, pero es un hombre paciente, sabe negociar y respeta la ética.

\section{Una auténtica fiesta popular}

Para muchos brasileños, el 10 de enero de 2003 quedará como una fecha inolvidable. Fue un día de alegría, una verdadera fiesta. Hubo cerca de 300.000 personas en la inmensa explanada de los ministerios y en la 'plaza de los tres poderes', adornadas por los colores de Brasil (verde y amarillo) o los del PT (rojo con una estrella blanca), agitando innumerables banderas. La alegría era desbordante, contagiosa. Todo un pueblo, de pie, feliz, lleno de esperanza y de sueños. Muchos creían soñar: había por fin llegado este día en que Lula, uno de los suyos, llegaría a presidente. Era la fiesta de todos los que nunca dejaron de esperar, y de luchar, para que esto sucediera. Se sentían de nuevo ciudadanos, actores, responsables. Volvían a encontrar su historia, su país, su futuro y su dignidad. Sin miedo a ser felices, hoy y mañana. "La esperanza ha vencido al miedo": estas fueron las primeras palabras de Lula, una vez elegido presidente. Esta esperanza podría estallar en este nuevo año. 
Y es que Lula ha expresado magníficamente esta esperanza de todo un pueblo en su primer discurso al Congreso, retransmitido a todo el país, inmediatamente después de su investidura: "El cambio es la palabra clave, el mensaje dirigido a los electores... La esperanza ha vencido al miedo. La sociedad ha decidido que ya había llegado la hora de seguir nuevos caminos frente a un modelo agotado que, en vez de crecimiento, ha producido estancamiento, paro, hambre, cultura del individualismo, indiferencia con relación al prójimo y desintegración de las familias... Mientras que haya un hermano o una hermana brasileña que padezca hambre, todos deberíamos sentirnos avergonzados... Si todos los brasileños pueden, todos los días, al final de mi mandato de cuatro años, tomar su desayuno, su almuerzo y su cena, yo habré cumplido la misión de mi vida... Ha llegado el momento de hacer de Brasil la nación en la que hemos soñado durante tanto tiempo, una nación soberana, digna, consciente de su importancia en la escena internacional y capaz de proteger y de tratar a todos sus hijos con justicia"...

Bien es verdad que este cambio no va a producirse a base de "actos voluntaristas", sino que debe ser conducido "con valentía y prudencia, paciencia y perseverancia", por medio del "diálogo y la negociación", porque "no podemos cosechar los frutos antes de plantar los árboles".

Más tarde, después de haber recibido la banda presidencial, dirigiéndose más directamente a la muchedumbre, Lula añadió que, a pesar de las dificultades, "no hay ningún hombre en la tierra más optimista que yo hoy, y os dijo que vamos a ayudar a este país... yo os trataré con el mismo respeto que trato a mis propios hijos".

\section{La hora de la acción}

Lula se fijó tres criterios a la hora de elegir a sus ministros: personas íntegras, imbuidas de ética; personas competentes; personas con sensibilidad social. En su discurso de investidura, todos los ministros han marcado claramente la diferencia y la voluntad de cambio, subrayando los objetivos sociales del nuevo gobierno. El gobierno no es homogéneo, pero transmite una imagen de competencia y de apertura.

Objetivo indispensable: el equipo se ha sabido ganar la confianza de los mercados. Esta confianza representa la vía de la gestión responsable y rigurosa; rechaza todo incumplimiento de reembolso de la deuda y quiere mantener los objetivos de inflación. Sin embargo, Antônio Palocci, ministro 
de finanzas, no ha tenido miedo de afirmar que la política principal no es la política financiera sino la política social. El equipo quiere promover el crecimiento económico y relanzar un cierto 'desarrollismo' por la sustitución competitiva de las importaciones.

Pero el país espera resultados sobre todo del equipo social. Nada será fácil, porque los servicios públicos fueron desmantelados y los recursos son muy limitados. Lula no deja de subrayar la prioridad por lo social, pero también les pide a los pobres que no esperen milagros. Durante el primer año las restricciones financieras serán inevitables y duras. En educación, sanidad, seguridad social, reforma agraria, seguridad alimentaria, lucha contra el hambre, etc., Lula ha puesto a políticos, creadores y emprendedores, más que administradores. Habrá tensiones, porque se han creado nuevos cargos que no van a tener los medios financieros para actuar.

También el equipo 'de gobierno' (interior y justicia, relaciones exteriores, medio ambiente, defensa, etc.) inspira confianza y esperanza. Todos sus miembros son figuras conocidas y admiradas en el país por su integridad y sus valientes acciones públicas a favor de la justicia y de los derechos humanos.

Lula ha conseguido formar un gabinete de apertura y de cambio, que tranquiliza y da confianza al mismo tiempo. La aprobación es casi general. Las primeras medidas del Presidente fueron también fuertemente simbólicas, con el fin de marcar su determinación de combatir la exclusión y liberar créditos sociales: la compra de treinta aviones de caza será retrasada varios años; no se comenzarán en 2003 nuevas obras en carreteras y el ejército va a participar en la construcción de las que están en marcha; el primer viaje del Presidente fue con todos sus ministros - una 'caravana del hambre'- para visitar aquellos lugares de gran pobreza en el Nordeste del país; Lula y varios ministros participan en el 3o Foro Social Mundial de Porto Alegre, a finales de enero; el gobierno brasileño intenta intervenir como mediador en la crisis de Venezuela.

Podemos destacar cuatro campos de trabajo principales:

Gobernar. Lula ha sido elegido para el cambio, para cambiar las estructuras sociales desfasadas, demasiado desiguales. La vía más fácil sería llegar a un acuerdo en torno a este objetivo entre los diversos sectores de la sociedad. Pero las contradicciones de clase existen, y las 'élites' no tienen la intención de renunciar fácilmente a sus privilegios. A corto plazo no podrá haber cambios profundos. Aumentará la polarización entre los que deben 
ceder y los que merecen ganar. Para superar las tensiones, el gobierno intenta negociar un Pacto Social entre los diferentes actores sociales. Existen contradicciones en el seno del gobierno y del parlamento, y la predisposición para la conciliación y el consenso es escasa.

Comienza un nuevo proceso político. No existe una clara mayoría presidencial. Lula deberá dar pruebas, al mismo tiempo, de habilidad y de autoridad políticas. Es un negociador y ha sido elegido por el número de votos más elevado de la historia del país. La designación de J osé de Alencar, industrial, como vicepresidente, le asegura el apoyo de una parte del empresariado. Por un lado, Lula deberá negociar continuamente con los diferentes partidos políticos pero, por otro lado, podrá contar con la poderosa organización y capacidad de movilización de los movimientos sociales y de otros actores sociales, de los que se siente naturalmente cercano, y que han contribuido tanto a su victoria, sin que estén dispuestos a dejarla escapar. Se inaugura así una nueva forma de democracia con una participación consciente más fuerte de las fuerzas sociales activas para el desarrollo del país.

Hambre cero. El programa de lucha contra el hambre y la miseria no puede aislarse del resto de reformas sociales estructurales. Lula ha mencionado muchas veces la necesidad de poner en marcha una serie de reformas: agraria, de los impuestos, de los partidos políticos, de la Seguridad Social y del trabajo. Seguramente no será demasiado difícil garantizar a todos 3 comidas diarias durante una semana, un mes o varios meses, pero no es tan simple establecer cambios duraderos. Las instituciones internacionales, e incluso el conjunto de los ciudadanos, estarán dispuestos a apoyar para arreglos temporales, pero ¿qué pasará si se toca la estructura misma de la distribución de la riqueza y del poder?

La perspectiva de suprimir la miseria y la pobreza de forma durable es inalcanzable sin la movilización de una gran parte de la sociedad, y sin la integración de los marginados en el circuito de la producción y del acceso a los bienes sociales. Toda una nueva concepción de la economía solidaria alternativa -de la que existen ya numerosas experiencias en Brasil- debería desarrollarse de forma considerable en los próximos años.

Economía social. La orientación económica principal consiste en red efinir una política económica nacional. Pesarán mucho los compromisos anteriores adquiridos, al menos durante el primer año. El país tiene una inmensa necesidad de créditos; y éstos van a depender de lo que el gobierno de Lula diga y haga. 
La prioridad de los años de FHC fue la estabilidad monetaria; en el imaginario popular, Lula representa la lucha contra las desigualdades y, para los productores, el relanzamiento del crecimiento económico. El FMI preconiza la continuidad. La perspectiva del 'crecimiento con equidad' significa la formación de un nuevo eje nacional de poder económico y político orientado: a la satisfacción de los derechos sociales de los más desfavorecidos, al incremento de las inversiones públicas y privadas para la infraestructura económica, a la consecución de un saldo positivo mayor de la balanza comercial, y al crecimiento de la inversión productiva privada, en particular, a favor de la industria nacional.

La ejecución de estas orientaciones supone volver a alimentar el presupuesto de la Seguridad Social, las inversiones sociales del BNDES 8 y de las empresas públicas que han sobrevivido a las privatizaciones. Eso exige además una recuperación de las políticas nacionales de desarrollo industrial y agrario, pero también la reinserción de los sectores de producción rural o urbana, familiar o comunitaria, que hoy por hoy se encuentran excluidos de la economía de mercado y de las políticas públicas.

El crecimiento con equidad - 'la economía para responder a la esperanza'no es posible sino contrarrestando la herencia de los años de marasmo. La reconstrucción de la economía brasileña puede apoyarse sobre el enorme mercado interno, actual y potencial. Ello significa romper con varias de las recetas del FMI. ¡El desafío es inmenso!

Soberanía nacional. Brasil puede enorgullecerse de una rica tradición de política exterior. Como presidente, FHC gozó de un prestigio real en el extranjero; sin embargo, durante su mandato, Itamaraty ${ }^{9}$ vivió un período de sombra: Mercosur está moribundo, la integración de América del Sur no ha progresado y los intereses del país parecían mal defendidos en las negociaciones comerciales. Lula quiere recuperar un cierto prestigio en la influencia del país y defender mejor su soberanía. Se dará prioridad a la reconstrucción de Mercosur y a la integración de la región. El nombramiento del ministro de asuntos exteriores y de su secretario general (viceministro) marca una clara ruptura.

8 El BNDES (Banco Nacional de Desarrollo Económico y Social) es el principal fondo público de inversiones.

9 Itamaraty es el nombre del palacio del ministerio de asuntos exteriores. 
Brasil se encuentra embarcado en varias negociaciones comerciales complejas de implicaciones duraderas (en particular, la Ronda Doha de la OMC ${ }^{10}$, el $\mathrm{ALCA}^{11}$ y Mercosur-Unión Europea). No se trata sólo de comercio, sino de disposiciones normativas que conciernen a todas las dimensiones de la soberanía económica del país. En las condiciones actuales de negociación, el ALCA conduciría a una pérdida de control de ciertos instrumentos económicos, financieros, industriales y tecnológicos, indispensables para poner en marcha una política económica nacional, instrumentos que los países ricos utilizan todavía en gran medida.

Lula y su ministro no han dejado de expresar sus inquietudes en cuanto al futuro de estas negociaciones. Resulta vital que Brasil mantenga 'los espacios de flexibilidad para nuestras políticas de desarrollo social, ecológico, agrario, industrial y tecnológico'. Lula quiere preservar en las negociaciones 'Ios derechos soberanos del pueblo brasileño para decidir acerca de su modelo de desarrollo'. Las actuales condiciones de negociación son totalmente asimétricas, como si la flexibilidad comercial debiera darse en un único sentido. Existe el riesgo de que se acentúe la tensión, ya que 'la integración' comercial de todo el continente es una de las estrategias prioritarias de la actual administración estadounidense para reforzar su hegemonía y su dominación.

\section{Conclusión}

Hoy en día, en América Latina, y en el mundo entero, muchos países dirigen su mirada con esperanza hacia Brasil. ¿El rigor puede generar más igualdad? Lula y su gobierno están decididos a combatir la miseria y la exclusión y, para ello, a afrontar muchos obstáculos. Disponen de algunas bazas favorables: la agricultura es próspera, la industria competitiva, hay grandes superficies de tierra disponible, la población es joven, emprendedora y busca formarse. 'Dios es brasileño', como les gusta decir por aquí. Pero el margen de maniobra sigue siendo limitado, teniendo en cuenta que la herencia del gobierno de FHC es pesada y hostil. Para transformar las estructuras, el apoyo popular y la participación de toda la sociedad civil serán indispensables. Pero no serán suficientes. Será decisiva la actitud del FMI, del Banco

10 Organización Mundial del Comercio.

11 El Área de libre comercio de las Américas, promovida por Estados Unidos. 
Mundial y de los grandes países industriales, en particular de los Estados Unidos. Lula pretende aco meter los objetivos tantas veces proclamados por estas instituciones y por el G-8. No vendrían mal algunos signos simbólicos favorables por parte de estas instituciones para calmar los mercados financieros mundiales. Negarse a apoyarle no sería sino la confesión de una gran hipocresía. 